Rev. Interd. em Cult. e Soc. (RICS), São Luís, v. 6, n. 2, p. 72-85, jul./dez. 2020

ISSN eletrônico: $2447-6498$

\title{
As implicações da covid-19 na vida "Social": crise política e desarranjo socioinstitucional ${ }^{1}$
}

\section{The implications of covid-19 to "Social" life: political crisis and social-institutional derangement}

\author{
JOSÉ HENRIQUE SOUSA ASSAI \\ Professor Adjunto de Filosofia no Curso de Ciências Humanas (UFMA). \\ jhs.assai@ufma.br
}

\begin{abstract}
RESUMO
A crise epidemiológica da covid-19 demonstrou a ineficiência de um plano governamental acerca da saúde pública no Brasil; mais do que isso, ela trouxe consigo um corolário remissivo de uma crise social sem precedentes. Perante o cenário pandêmico da covid-19 e levando em consideração os ancoramentos teórico-metodológicos da teoria crítica e da filosofia social, quero explicitar nesta pesquisa que essa crise social não pode ser debitada unicamente na conta da covid-19, porém ao desarranjo social que ela evidenciou. Daí que, a meu ver, esse estado de crise social decorre da não-efetivação da esfera do "Social" entendido basicamente pelas relações, instituições e práticas sociais (1). Tomarei como referências um dual quadro categorial: (2) a crise nas práticas e relações sociais mediante uma debilitada compreensão do que seja ideologia (quadro político) e a crise institucional entre os poderes (3).
\end{abstract}

Palavras-chave: Filosofia Social. Teoria Crítica. Covid-19. Patologia Social.

\begin{abstract}
The epidemiological crisis from covid-19 demonstrated the inefficiency of a governmental plan on public health in Brazil; moreover, it brought with it a corollary which refer to an unprecedented social crisis. In front of pandemic scenario of covid-19 and taking into account the theoretical-methodological assumptions of critical theory and social philosophy, I want to make explain in this research that this social crisis can't be debited just because of covid-19, but to the social derangement which it highlighted. From my the point of view this social crisis derive from the not-effectuation of the "Social" sphere basically understood by social relations, institutions and practices (1). As of this issue, I will take as reference a dual categorical framework: (2) the crisis in social practices and relations through a weakened understanding with regard to ideology (political framework) and the institutional crisis between the public powers in our Republic State (3).
\end{abstract}

Keywords: Social Philosophy. Critical Theory. Covid-19. Social Pathology.

\section{COVID-19 E A EROSÃO "SOCIAL" NO BRASIL}

O desiderato do atual governo mediante suas ações políticas testemunha uma situação de crise social, política e institucional (NOBRE, 2020, 80p.) eivada de contradições (SCHWARCZ, 2019, p.273). O caos epidemiológico oriundo da covid-19 também demonstrou, pari passu, não apenas a precária situação da saúde sob o quadro de uma política pública voltada para o povo brasileiro, mas, também a cabal instabilidade social e política do (no) Brasil decorrida pelo desarranjo do déficit efetivo de políticas públicas impactando, assim,

\footnotetext{
${ }^{1}$ Artigo submetido para avaliação recebido em 23/09/2020 e aprovado em 30/10/2020.
} 
Rev. Interd. em Cult. e Soc. (RICS), São Luís, v. 6, n. 2, p. 72-85, jul./dez. 2020

ISSN eletrônico: $2447-6498$

fortemente na vida das pessoas e gerando uma radical alteração no ordenamento social: mudanças radicais nas ações individuais e coletivas em todos os segmentos sociais (SOBRINHO, 2020, 457p., GUEDES, 2020, p. 1 - 9, LIMA, 2020, p. 175 - 187). Aliás, há fortes indicações de que desde o último pleito eleitoral à presidência da República (ASSAI, 2020, p.55 - 66) o nosso país se enredou em uma tantalizante crise sistêmica especificamente no campo social, político e econômico.

A leitura diagnóstica supracitada não se dá por mero acaso e "de carona" ao covid-19. Não! Ela toma por consideração os pressupostos de uma teoria crítica e de uma filosofia social (DETEL, 2007, 191p., HERRMANN, 2018, 197p., JAEGGI, 2017a, 128p., PARIJS, 2017, 384p., PINZANI, 2013a, 241p., PINZANI, 2013b, 216p.) nos quais procuram encetar não apenas um diagnóstico crítico (ANTUNES, 2018, 304p., NOBRE, 2008, 302p., MÉSZÁROS, 2004, 559p., JAEGGI, 2013, p. 266 - 295., ROSA, 2019, 681p., SANTOS, 2007, 126p., SILVA, 2019, 224p., SOUZA, 2020, 248p., SOUZA, 2018a, 247p., SOUZA, 2018b, 288p.) de uma determinada realidade, mas, sobretudo, as ações atitudinais de análise e correção (WESCHE, 2013. p.193 - 220., SEN, 1981. 257p., ALLEN, 2015, p.513 - 529.) dessa mesma realidade. Nesse sentido, ainda que a "espada de Dâmocles" esteja sob as nossas cabeças por causa da patológica situação ocasionada pela covid-19, não se pode olvidar, sob o ponto de vista sociopolítico, o que esteja ocorrendo no hodierno cenário brasileiro: a culpa não é da covid19, porém ela "oportunizou" a todos nós sermos afetados pela sintomatologia do "Social" (JAEGGI, 2017a, 128p.) na qual nos encontramos, e de modo precípuo, um cenário pandêmico promovido pelo movimento ideológico pela atual gestão governamental (JAEGGI, 2008, p.137 - 165., KRENAK, 2020, 18p.). É com base nesses pressupostos que eu explicitarei nesta pesquisa duas situações atuais decorrentes da erosão do "Social" nas quais encontram-se enredadas pelo corolário remissivo ao cenário pandêmico da covid-19: em primeiro lugar, (2) uma crise situacional nas práticas e relações sociais mediante o movimento ideológico subjacente ao atual governo que intenta em obliterar qualquer tentativa de diálogo e de crítica; em segundo, (3) a crise institucional entre os poderes na qual derrete o equilíbrio socioinstitucional promovendo uma efetiva disrupção na fisiognomia sociopolítica brasileira. Faz-se necessário, contudo, apresentar primeiramente o conteúdo daquilo que se entende pela esfera do "Social" e em que sentido a situação pandêmica ocasionada pela covid-19 "auxiliou" nessa erosão sistêmica do esteio "Social" brasileiro. 
Rev. Interd. em Cult. e Soc. (RICS), São Luís, v. 6, n. 2, p. 72-85, jul./dez. 2020

ISSN eletrônico: $2447-6498$

\subsection{O 'Social”' como mediação para uma pesquisa crítica}

A pesquisa crítica entendida também por teoria crítica tem em seu escopo primordial uma forma de saber multifacetada, isto é, não é possível afirmar decididamente que exista apenas uma teoria crítica, mas, sim, existem teorias críticas (FORST, 2009, p. 743). No interior dessa pluralidade reside, entretanto, um espírito autocompreendido por um dever-ser; isto é, as três fases procedimentais de uma pesquisa crítica supracitadas são mediações consubstanciadas por uma efetiva transformação de uma determinada realidade (JAEGGI, 2017b, p. 209 - 224). De fato, o movimento proposto pela teoria crítica ainda levando em conta sua pluralidade epistêmica é o êxodo do "o que é" para "o como deve ser" uma dada situação epocal. Nesse caso, a mudança para uma "melhor condição" não ocorre simplesmente pelo puro arbítrio dos partícipes da ação social e política (GILBERT, 2014, p.449.); mas, ela é fundada numa crítica de cunho imanente dos seus próprios pressupostos (STAHL, 2013, p.475). Daí que a ideia do "Social" emerge como uma mediação constitutiva de uma pesquisa crítica na qual leve a sério o telos da emancipação (transformação efetiva). Tal procedimento não reside apenas em uma teoria crítica, mas, de modo particular, também orienta a filosofia social na qual se articula tomando por base essa categoria temática - "Social" - entendida pelas "práticas sociais, instituições e relações sociais; portanto, de nossas formas de vida sociais" (JAEGGI, 2017a, p.128).

A compreensão pelo "Social” orienta o pensar filosófico social para duas perguntas básicas: “o que devemos fazer (e por que?)”. Só que no entendimento de Rahel Jaeggi, o Social passa a ser entendido como instância de metarreflexão. Essa forma de pensar da filósofa alemã parece encetar um vestígio de um modo filosófico (justificação) de pesquisa. Não cabe perscrutar essa questão aqui, mas permanece como uma perspectiva de investigação. A filosofia social, portanto, estabelece como matriz de estudo e pesquisa o "Social" no interior de um design conceitual quaternário: práticas sociais, instituições sociais, relações sociais e, por fim, formas de vida (JAEGGI, 2014, p.451). As práticas sociais são ações realizadas coletivamente nas quais podem ser executadas por meio das relações sociais bem como nas instituições sociais (JAEGGI, 2014, p. 96 - 97). Para Jaeggi, uma determinada prática para ser considerada como social não basta apenas realizada coletivamente, mas deve consistir em uma autocompreensão regulativa na qual estabelece algum objetivo específico (JAEGGI, 2014, p. 98 100). Por isso que para Jaeggi uma prática social está vinculada a uma determinada forma de vida que, por sua vez, é definida como "o conjunto de práticas sociais juntamente com seus ordenamentos e procedimentos sociais" (JAEGGI, 2014, p.77). Se assumimos essa compreen- 
Rev. Interd. em Cult. e Soc. (RICS), São Luís, v. 6, n. 2, p. 72-85, jul./dez. 2020

ISSN eletrônico: $2447-6498$

são, podemos afirmar que as práticas sociais foram e estão sendo afetadas em todo o mundo pela covid-19. Nenhuma sociedade está imune a tal mudança.

É certo que a covid-19 alterou radicalmente o modo de ser das práticas, instituições e das relações sociais afetando a vida como um todo no Brasil (COTA, 2020; IBGE, 2020) e no restante do planeta gerando, dentre tantas mazelas, uma forma de alterofobia - medo da alteridade - fomentando disruptivamente o distanciamento não apenas social, mas até de si mesmo. Daí as crises de caráter psicológicos eclodirem nesse momento de pandemia epidemiológica e sanitária (SAFATLE, 2018. 267p., JR, 2020). Por isso, sob o ponto de vista do nosso pensar e agir, como uma possibilidade de responder a todo esse cenário restritivo provocado pela covid-19, emerge a ideia de uma ética solidária (JAEGGI, 2001. p. 287 - 308) capaz de enfrentar a supracitada alterofobia bem como ao desarranjo social ocasionado pela SARSCOV 2. Aliás, ações sociais cognominadas por solidariedade estão em voga nesse momento de pandemia. O "Social", portanto, é afetado e não apenas em sua constituição nas práticas sociais até então costumeira e efetivamente construídas, mas também na vida das instituições e relações sociais. Para esta pesquisa, tomando como referência a ideia do "Social" ancorada nos pressupostos de uma teoria crítica e da filosofia social, eu me inclinarei doravante para as duas considerações ora supracitadas: a primeira, a crise no "Social" brasileiro é agudizada por uma forma ideológica do governo pautar suas estratégias políticas e sociais; a segunda, a aguda crise "Social", conforme dado conceitual acima delineado, desencadeada entre os poderes republicanos, mais especificamente entre o executivo e o judiciário.

\section{IDEOLOGIA COMO PONTO DE INFLEXÃO NO "SOCIAL" BRASILEIRO}

Se pela esfera "Social" entende-se as práticas, relações e instituições sociais - observadas aqui a definição de cada uma delas pela filosofia social da filósofa alemã Rahel Jaeggi - então, sob o ponto de vista de uma teoria crítica entendida em seu escopo precípuo pelo diagnóstico, pela análise e correção - atitude transformadora - (WESCHE, 2013, p.200) em uma determinada realidade, podemos aferir que uma prática social estrategicamente articulada mediante o ordenamento político atualmente em nosso país constitui-se em uma "anátema às ideologias". Tal ação fere o esteio "Social" na medida em que causa um desequilíbrio no agir político de modo geral.

No discurso de posse do presidente Bolsonaro uma das questões centrais por ele arroladas foi exatamente o mote "ataque às ideologias". Naquela ocasião, uma específica concepção de mundo social e político fora apresentada para a esfera pública (AVRITZER, 2004, p.703 - 728, AVRITZER, 1999, p. 18 - 43, HABERMAS, 2003, 397p., LUBENOW, 2010, 
Rev. Interd. em Cult. e Soc. (RICS), São Luís, v. 6, n. 2, p. 72-85, jul./dez. 2020

ISSN eletrônico: 2447-6498

p.227 - 258) deslindando-se em quatro aspectos: libertar o país tanto da submissão ideológica quanto das amarras ideológicas, combater a ideologia de gênero e, por fim, conduzir uma economia sem viés ideológico. Esse design político não está apenas no discurso enquanto mediação pragmática para determinados fins (HABERMAS, 1995, p.606), mas, sobretudo, expressa uma forma disruptiva de entendimento e de ação para com o esteio "Social", pois, sob o plano mais elementar, ao insistir que o governo deveria assumir uma posição contrária radicalmente às ideologias, tal posição já assume prima facie um específico modo compreensivo ideológico eivado de contradição performativa (ASSAI, 2020, p. 55 - 66). Permanece, entretanto, o desafio de entender o que significa, de fato, uma concepção ideológica e a sua relação com o mundo "Social" apresentado nesta pesquisa.

Parece pouco defensável apelar para o conceito de ideologia apenas como um conjunto de ideias do puro arbítrio quer seja subjetivo quer seja coletivo. Ao recepcionarmos nesta pesquisa os pressupostos de uma teoria crítica, penso que se possa alargar tal compreensão na medida em que devemos relacioná-la reflexiva e criticamente com o "Social”. Nesse sentido, uma ideologia ou mecanismo ideológico é um conjunto de "ideias que (necessariamente ou, pelo menos, sistematicamente) surgem e subsistem em determinados contextos. Ideologias são, portanto, sistemas de convencimento, mas que têm, ademais, consequências práticas. Elas têm efeito prático e são, por sua parte, efeitos de uma determinada práxis social" (JAEGGI, 2008, p.139).

Exatamente nesse conceito estão presentes tanto a esfera da prática social quanto a noção básica de uma ideia (aparato cognitivo) que se efetiva no esteio da sociedade (ordenamento filogênico). Assim, sob o viés da pesquisa crítica (teoria crítica) e da filosofia social, uma determinada forma ideológica possui duas situações: por um lado, o "que está na mente" humana está vinculado com uma determinada prática social; por outro, cada mecanismo ideológico pode ser visto como uma forma socionormativa (um dever-ser que tenha um telos emancipatório, de efetivação das condições mínimas de existência social, no qual é criticamente e permanentemente ponto de reflexão em um contexto social) de mundo ou não-normativa (não está sob o crivo da emancipação). A título de exemplificação que nos assiste nesta pesquisa, no primeiro caso, e tomando por conta o caos da covid-19 na sociedade, criar leitos hospitalares, melhores condições de trabalho aos profissionais da saúde, a testagem em massa como possível estratégia de combate ao coronavírus, ter um plano epidemiológico e sanitário (o que inclui o não menos discutido e problemático marco regulatório do saneamento básico), dar continuidade ao FUNDEB, aperfeiçoar as políticas institucionais das organizações da sociedade civil (Lei n. 13.019/2014) são consideradas como mediações fundamentais para a efeti- 
Rev. Interd. em Cult. e Soc. (RICS), São Luís, v. 6, n. 2, p. 72-85, jul./dez. 2020

ISSN eletrônico: 2447-6498

vação das condições de existência social (PINZANI, 2013a, 241p., PINZANI, 2013b, 216p., PINZANI, 2011, p. 83 - 101). Nesse caso, um conjunto de ações afirmativas desse porte, de políticas públicas comprometidas com a sociedade e, portanto, com o "Social", é conditio sine qua non para garantir e efetivar a vida humana na sociedade. Tais ações são construídas ideologicamente, isto é, elas são mecanismos ideológicos na medida em que se tem um conjunto de ideias e que essas possuem consequências muito práticas na sociedade.

\subsection{E como a noção de ideologia se vincula com atual prática governamental a ponto de erodir o "Social" brasileiro?}

Retomando o âmago discursivo da tomada de posse do Presidente Bolsonaro, podemos identificar uma quaternária característica consubstanciada por não menos uma deficitária noção da própria ideologia e essa situação causa transtornos ao "Social". Naquela ocasião - e não ficou só nela - o plano político era a total supressão e aniquilação de quaisquer ideologias minimamente relacionadas com o governo Lula e Dilma respectivamente. Os conteúdos assertóricos proferidos no palanque não foram meros "eufemismos", a saber: submissão e amarras ideológicas, combater a ideologia de gênero e conduzir a economia sem viés ideológico; pelo contrário, essas sentenças assertivas expressam a radical adesão a um projeto populista (NOBRE, 2020, 80p., KALTWASSER, 2017, p.903) no qual confunde propositalmente a ideia de ideologia com política de governo como se esse último não estivesse eivado de ideologias. Como explicitei, qualquer pensamento associado a uma ação já é uma construção ideológica; portanto, apelar para a ilação de que o "Brasil acima de tudo" estaria e está desprovido, desvinculado, de qualquer ideologia não me parece defensável.

Pensar e agir contra uma ideologia " $x$ " é também uma forma ideológica de pensamento e ação. Por exemplo, quando o governo afirma que conduzirá a economia brasileira "sem viés ideológico", tal posição assumida é ideológica. Aliás, por tudo que presenciamos até agora nessa orientação do plano econômico, justifica-se uma análise e correção críticas (FLICKINGER, 2003, p.176., HERZOG, 2017, p.335, HERZOG, 2014, p.207, HONNETH, 2015, p. 167, SANTOS, 2007, p.126., SILVA, 2019, p.224, SOUZA, 2018a, p.247, SOUZA, 2018b, p.288); mas, pelo visto o próprio governo não se submete a esse escrutínio. O "Social” brasileiro é pulverizado por essa posição atitudinal do governo ao estabelecer que essa "intifada política" contra as ideologias se torna o novo "marco regulatório" para um "Deus acima de todos". O que não seria mais ideológico do que um pensamento religioso-metafísico voltado para uma sociedade laica e civil? (HABERMAS, 1990, p.271, HABERMAS, 2012, p.334, 
Rev. Interd. em Cult. e Soc. (RICS), São Luís, v. 6, n. 2, p. 72-85, jul./dez. 2020

ISSN eletrônico: $2447-6498$

HABERMAS, 2019, p.1752). Não! Isso não é ideologia, é apenas o "Deus acima de todos" para um "Brasil acima de tudo"!

Reitero que o "Social” brasileiro encontra-se, de igual modo e lamentavelmente como muitos brasileiros (as), na UTI, em uma tantalizante agonia, pois, as práticas e relações sociais são afetadas diretamente na vida societária, já que elas não apenas são deslocadas de um escrutínio crítico e reflexivo para fins de correção atitudinal política, mas também essas mesmas práticas e relações sociais são "populisticamente" desenvolvidas por uma meta-ideologia (um mecanismo ideológico autocompreendido como superior a todos os demais modos ideológicos de pensamento e ação). Sim! Há uma narrativa arquetipal que açambarca toda a sociedade: o conteúdo político e ideológico do atual governo se estabelece como uma "pedra de Sísifo" para o povo brasileiro: os bens sociais e fundamentais (BRUNKHORST, 2002, p.247, HELFER, 2012, p. 163 - 186.) não são efetivados e a culpa é "das ideologias" que corroeram o Brasil até 2018. “Tá ok?!” As ações e estratégias políticas "sisifunianamente” articuladas de modo "meta-ideológico" fazem parte de um pérfido escopo precípuo do flagelo acometido ao "Social" brasileiro. Talvez a terapia seja um pensar e um agir de modo "palimpsesto" em nossa história! E por isso mesmo que uma atitude crítica socionormativa construída ideologicamente - e não poderia ser diferente - seja uma mediação necessária para a correção dessas distorções. Na esteira do desarranjo no "Social" brasileiro resta para esta pesquisa a última abordagem: a meta-ideologia que debela o "Social" no Brasil está também presente nas relações institucionais e, nesse caso, a alérgica relação entre Executivo e Judiciário é digno de nota.

\section{A CRISE ENTRE OS PODERES REPUBLICANOS NO "SOCIAL" BRASILEIRO}

A tradição ocidental assumiu, desde Montesquieu, pelo menos enquanto um conteúdo substantivo ao aferimento para um republicanismo democrático, a métrica tripartite dos poderes (MONTESQUIEU, 2007, p.727) buscando nessa articulação uma equilibrada relação. Essa questão não é uma causa finita, pois nessa mesma tradição assentam-se posições divergentes acerca de qual é a melhor forma de governo e como ela é possível. Mesmo tal discussão ser inconclusiva emergiu na sociedade brasileira, particularmente desde o último pleito eleitoral, um ressurgimento de posições mais centralizadoras fomentando o desiderato remissivo de uma forma de poder autocrática que tem nas Forças Armadas e no chefe do Executivo (bem como em todo o seu gabinete) o primado da sua gestão. Esse cenário consubstanciado pela meta-ideologia do "ponto final" e do "tá ok" - expressões que se consolidam não apenas enquanto jargões de um governo, mas de uma lógica de pensamento e ação de uma forma eco- 
Rev. Interd. em Cult. e Soc. (RICS), São Luís, v. 6, n. 2, p. 72-85, jul./dez. 2020

ISSN eletrônico: 2447-6498

nômica neoliberal deletéria para a vida "Social" do povo brasileiro - pode ser entendido analiticamente em dois momentos: o primeiro, que vai desde os primórdios da corrida eleitoral (2018) até o proferimento discursivo do Presidente Bolsonaro em sua tomada de posse; o segundo, a partir da posse, os contínuos rearranjos internos do Executivo e Legislativo para efetivar suas estratégias políticas, sociais e econômicas cognominadas aqui categorialmente por meta-ideologia. Por essa lógica neoliberal creio que as considerações feitas por Marcos Nobre são bem contundentes:

[...] Quem conseguir entender a expressão "a democracia da ditadura era a verdadeira democracia" conseguirá entender Bolsonaro. Quem conseguir entender isso, entenderá também como isso se liga ao pretenso liberalismo de Paulo Guedes, por exemplo. Só no discurso o liberalismo de Guedes inclui um elemento básico da doutrina liberal, o ataque a protecionismos de todos os tipos. Na prática, Guedes mantém e reforça protecionismos vários. Seu liberalismo se limita à austeridade fiscal. No mais, é um liberalismo que só funciona para estimular e justificar as práticas mais selvagens de parte da base bolsonarista. É um "liberalismo" que se coaduna perfeitamente com ausência de regulação ambiental, com desmatamento, garimpo em terras indígenas, uso indiscriminado de agrotóxicos, supressão de toda proteção social que for politicamente viável suprimir, militância pela suspensão do isolamento e das quarentenas para tentar conter a taxa de transmissão e de contágio pelo Sars-CoV-2, estímulo à retomada imediata de toda atividade econômica em pleno pico de transmissão pandêmico. (NOBRE, 2020, p. 20).

Retomando, a despeito da covid-19 e todo o corolário daí decorrido principalmente em virtude de uma célere resposta por parte do governo brasileiro no que diz respeito a um plano epidemiológico e sanitário capaz de lidar com a SARS-COV-2, temos que a exequibilidade desse plano meta-ideológico, conforme supracitado, foi uma enchança para os recentes e episódicos embates entre os poderes Executivo e Judiciário. Esses enfrentamentos provocaram uma forma de desequilíbrio no "Social" já que se trata da dimensão institucional entre os poderes republicanos. As recentes querelas e achaques entre o Executivo e o Judiciário retomou o debate protagonizado no filme "A Onda": autocracia "acima de tudo". Só que agora não se trata apenas de uma pesquisa e de um estudo acadêmicos como ocorreu no enredo verossímil do filme. Não! pelo contrário, agora, e de modo mais radical, a democracia agonizada por uma profunda crise (LEVITSKY, 2018, p.251) está sob o crivo do escrutínio de todo o povo brasileiro: se é democracia que queremos, como a queremos? Ou se não é democracia que desejamos, então o mote "quem não sabe para onde ir qualquer caminho serve" nos diz respeito?

Sob o ponto de vista da organização do poder no interior de um Estado constitucional (HÄBERLE, 2002, p.55; TAVARES, 2010, p.549; STRECK, 2009, p.594; LEITE, 2011, 
Rev. Interd. em Cult. e Soc. (RICS), São Luís, v. 6, n. 2, p. 72-85, jul./dez. 2020

ISSN eletrônico: $2447-6498$

p.798; GOMES, 2010, p.496) parece haver um mínimo de consenso de que para a efetivação e aperfeiçoamento das instituições enquanto formas diversas de poder é imperioso o fato do equilíbrio relacional entre as próprias instituições no esteio do Estado compreendido constitucional e republicamente. Então, afirmar que é necessário o contínuo diálogo entre os poderes no Estado republicano deve ser uma perene construção vinculativa para os poderes constituintes e não um mero mantra verborrágico. Os poderes Executivo, Legislativo e Judiciário demonstram a partir de 2018, mas não apenas nesse período, de quando em vez eventos nada construtivos para a democracia brasileira. Especificamente tanto o Judiciário quanto o Executivo testificam a pertinência da "teoria da quebra das regras informais das instituições" (NOBRE, 2020, p.80; LEVITSKY, 2018, p.251.), pois considera como

[...] referência mais próximo o período de transição do primeiro para o segundo mandato de Dilma Rousseff. Sustenta que a crise se instala a partir do momento em que o perdedor da eleição presidencial de 2014, o PSDB, decide questionar na Justiça o resultado. Nessa visão, as coisas iam relativamente bem com o presidencialismo de coalizão até que esse ato dá início a quebras de regra em série que culminam na eleição de Bolsonaro [...] A teoria da quebra das regras informais localiza a origem mais remota da crise na Constituição Federal de 1988, que teria imposto um desenho institucional cujas falhas construtivas teriam ficado evidentes a partir de 2014. Esta vertente explicativa sustenta que foi a adesão do sistema partidário a quebras de regra que já tinham sido praticadas antes pelo Judiciário - pelo STF, em especial - que levou a crise para o coração do próprio sistema político (NOBRE, 2020, p. $58-59)$.

Questionar uma norma é um direito da pessoa no exercício da sua cidadania. Aliás, não é apenas um direito, mas é de igual modo um ato legítimo sendo o constitucionalista o seu mediador e o poder judicial um intérprete dessa mesma norma para fins da ordem pública (HÄBERLE, 2002, p.55). O que nos remete ao nosso contexto desde 2014 intenta em uma forma divergente e até sub-reptícia ao que fora supracitado. Alguns episódios recentes-e não dá para ficar citando um por um aqui - entre os poderes Executivo e Judiciário macularam e ainda ferem o equilíbrio da esfera "Social" - particularmente nesse atual contexto pandêmico - na medida em que esses estranhamentos produzem efeitos disruptivos para a democracia e muito particularmente para o povo e, portanto, solapando a esfera "Social" que é também entendida pelas relações institucionais no interior de um Estado republicano e democrático.

Um desses episódios que ratifica essa condição limítrofe entre o Executivo e o Judiciário ocorreu por ocasião do STF ter encaminhado à Procuradoria Geral da República (PGR) uma notícia crime para apurar a fala da ministra da Mulher, Família e Direitos Humanos, Damares Alves. $\mathrm{O}$ argumento subjacente a tal contexto fora uma reunião ministerial em abril e 
Rev. Interd. em Cult. e Soc. (RICS), São Luís, v. 6, n. 2, p. 72-85, jul./dez. 2020

ISSN eletrônico: $2447-6498$

que naquela ocasião a ministra Damares disse que pediria a prisão de governadores e prefeitos perante a situação de pandemia e o pretenso erro dos chefes dos executivos locais na assistência social e em uma política de saúde comprometida com o combate ao covid-19. Como se não bastasse essa situação o mais recente episódio põe mais aziúme no ambiente interno do Executivo em uma das pastas não menos importante: Políticas de Promoção da Igualdade Racial do Ministério da Mulher, Família e Direitos Humanos. A ex-secretária apresentou fortes denúncias de ilegalidade em um convênio assinado pela pasta da ministra Damares. Esse é mais capítulo de uma pecha deletéria que faz erodir o esteio "Social", pois fragiliza não apenas as instituições em suas articulações internas, mas, sobretudo, promove uma sensação de disrupção social.

Por fim, e não menos significativo nesse contexto antes sinalizado, os recentes pronunciamentos do ministro Luiz Roberto Barroso põem em alerta a relação institucional entre o Executivo e o Judiciário em meio ao cenário da covid-19. Em agosto último, em um evento intitulado "Respostas constitucionais a retrocessos na democracia", o então ministro declarou que "Temos um presidente que defende a ditadura e a tortura e ninguém jamais considerou alguma solução diferente do respeito à igualdade constitucional”. A despeito das reações do GSI (Gabinete de Segurança Institucional) o fato mesmo é que esse cenário não apenas macula a nossa democracia ou pelo menos tende a macular; mas, principalmente, gera um óbice no exercício democrático para a efetivação administrativa em todos os setores do nosso país e, por conta da pandemia que grassa em todo o mundo e, portanto, no Brasil com altos índices, gera problemas nas tratativas institucionais entre os poderes repassando "essa conta" para um povo que se vê desassistido (saúde, INSS, segurança pública, desemprego etc.). A culpada não é a covid-19, porém ela serve como uma "espada de Dâmocles" sobre os poderes e, assim, quando ocorre a falta de uma equilibrada relação socioinstitucional entre eles, a esfera do "Social" passa a ser pulverizada. A continuar assim, talvez essa "espada" caia realmente sobre nossas cabeças. Talvez até seja o desejo de um(a) ou outro(a)! No entanto, ainda permanece para o povo brasileiro o desafio em continuar lutando para a efetivação de uma democracia participativa que possa responder aos desafios epocais como, por exemplo, o caso da covid19. Política pública sanitária e epidemiológica é apenas um lado desse cenário social e democrático, pois dele emana e decorre para o equilíbrio da vida "Social". 
Rev. Interd. em Cult. e Soc. (RICS), São Luís, v. 6, n. 2, p. 72-85, jul./dez. 2020

ISSN eletrônico: $2447-6498$

\section{REFERÊNCIAS}

ALLEN, Amy. Emancipation without Utopia: Subjection, Modernity, and the Normative Claims of Feminist Critical Theory, Hypatia, v. 30, n. 3, p. 513 - 529, 2015.

ANTUNES, Ricardo. O Privilégio da Servidão: o novo proletariado de serviços na era digital. São Paulo: Boitempo, 2018. 304p.

ASSAI, José Henrique Sousa. Pensando criticamente a "Realpolitik": A política de justiça social do programa "Mais IDH", Revista de Filosofia Aufklärung, João Pessoa, v.7, n.1., p. $55-66,2020$.

AVRITZER, Leonardo, COSTA, Sérgio. Teoria Crítica, Democracia e Esfera Pública: Concepções e Usos na América Latina. DADOS - Revista de Ciências Sociais, Rio de Janeiro, v.47, n.4, p.703-728, 2004.

AVRITZER, Leonardo. Teoria democrática, esfera pública e participação local, Sociologia, Porto Alegre, n.2, p. 18 - 43, 1999.

BRUNKHORST, Hauke. Solidarität: von der Bürgerfreundschaft zur globalen Rechtsgenossenschaft. 1. ed. Frankfurt am Main: Suhrkamp Verlag, 2002. 247p.

COTA, Isabella. América Latina busca saída para a crise econômica. Disponível em: <https://brasil.elpais.com/economia>. Acesso em 20 jul. 2020.

DETEL, Von Wolfgang. Philosophie des Sozialen. Stuttgart: Reclam, 2007. 191p. (Grundkurs Philosophie 5).

FLICKINGER, Hans Georg. Em nome da Liberdade: elementos da crítica ao liberalismo contemporâneo. Porto Alegre: EDIPUCRS, 2003. 176p.

FORST, Rainer et.al. Sozialphilosophie und Kritik. 1.ed. Frankfurt am Main: Suhrkamp Verlag, 2009. 743p.

GILBERT, Margaret. Joint Commitment: How We Make the Social World. Oxford: Oxford Press, 2014. 449p.

GOMES, Sergio Alves. Hermenêutica Constitucional: um contributo à construção do Estado democrático de Direito. 2. reimpr. Curitiba: Juruá, 2010. 496p.

GUEDES, Jozivan. Biopolítica e normatividade: duas abordagens filosóficas acerca da pandemia da Covid-19 a partir de Agamben e Habermas, Voluntas, Santa Maria, v.11, e. 8, p. 19, 2020 .

Instituto Brasileiro de Geografia e Estatística (IBGE). Pesquisa Pulso Empresa: Impacto da Covid-19 nas Empresas. Disponível em: <https://covid19.ibge.gov.br〉. Acesso em 20 jul. 2020.

HABERMAS, Jürgen. Auch eine Geschichte der Philosophie: Die okzidentale konstellation von Glauben und Wissen. Berlin: Suhrkamp Verlag, 2019. 1752 p. 2 v. 
Rev. Interd. em Cult. e Soc. (RICS), São Luís, v. 6, n. 2, p. 72-85, jul./dez. 2020

ISSN eletrônico: $2447-6498$

Verlag, 2012. 334p

Nachmetaphysisches Denken II: Aufsätze und Repliken. 1 ed. Berlin: Suhrkamp Mudança estrutural da Esfera Pública: investigações quanto a uma categoria da sociedade burguesa. 2.ed. Tradução Flávio Kothe. Rio de Janeiro: Tempo Brasileiro, 2003. 397p.

Vorstudien und Ergänzungen zur Theorie des Kommunikativen Handelns. 1. ed. Frankfurt am Main: Suhrkamp Verlag, 1995. 606p.

Pensamento pós-metafísico. Tradução Flávio Beno Siebeneichler. Rio de Janeiro: Tempo Brasileiro, 1990. 271p.

HÄBERLE, Peter. Hermenêutica Constitucional: a sociedade aberta dos intérpretes da Constituição: contribuição para a interpretação pluralista e "procedimental" da Constituição. Tradução Gilmar Mendes. Porto Alegre: Sergio Fabris, 2002. 55p.

HELFER, Inácio. Os bens sociais são sempre bens convergentes? Trans/Form/Ação, Marília, v.35, n.2, p.163 - 186, 2012.

HERRMANN, Steffen. Ich - Andere - Dritte: Eine Einführung in die Sozialphilosophie. München: Karl Alber Verlag, 2018. 197p.

HERZOG, Lisa (org.). Just Financial Marktes? Finance in a just society. 1. impr. Oxford: Oxford Press, 2017. 335p.

Freiheit gehört nicht nur den Reichen: Plädoyer für einen zeitgemäßen Liberalismus. München: C.H. Beck Verlag, 2014. 207p.

HONNETH, Axel. Die Idee des Sozialismus: Versuch einer Aktualisierung. Berlin: Suhrkamp Verlag, 2015. 167p.

JAEGGI, Rahel, CELIKATES, Robin. Sozialphilosophie: Eine Einführung. München: C.H.Beck, 2017a. 128p.

JAEGGI, Rahel. Crisis, Contradiction, and the Task of a Critical Theory. In: BARGU, Banu, Bottici, Chiara. Feminism, Capitalism and Critique: Essays in Honor of Nancy Fraser. Switzerland: Springer, 2017b. p. $209-224$.

JAEGGI, Rahel. Kritik von Lebensformen. 2.ed. Berlin: Suhrkamp Verlag, 2014. 451p.

JAEGGI, Rahel. Was ist Ideologiekritik? In: JAEGGI, Rahel, WESCHE, Tilo (org.). Was ist Kritik? 3.ed. Frankfurt am Main: Suhrkamp, 2013. p. 266 - 295.

JAEGGI, Rahel. Repensando a Ideologia. Civitas, Porto Alegre, v.8, n.1, p.137 - 165, 2008.

JAEGGI, Rahel. Solidarity and Indifference. In: MEULEN, Ter, ARTS, Will, MUFFELS, R. (org.). Solidarity in Health and Social Care in Europa. Dordrecht: Springer, 2001. p. 287 308. 
Rev. Interd. em Cult. e Soc. (RICS), São Luís, v. 6, n. 2, p. 72-85, jul./dez. 2020

ISSN eletrônico: $2447-6498$

JR, Everly. Navigating COVID-19's Mental Health Impact. Disponível em: < https://www.hopkinsmedicine.org/health/conditions-and-diseases/coronavirus/navigatingcovid-19s-mental-health-impact >. Acesso jul. 2020.

KALTWASSER, Cristóbal et.al. (org.). The Oxford Handbook of Populism. 1.ed. Oxford: Oxford Press, 2017. 903p.

KRENAK, Ailton. O amanhã não está à venda. São Paulo: Companhia das Letras, 2020. $18 \mathrm{p}$.

LEITE, George et.al. (coord.). Direitos, Deveres e Garantias Fundamentais. Salvador: Jus Podivim, 2011. 798p.

LEVITSKY, Steven, ZIBLATT, Daniel. Como as democracias morrem. Tradução Renato Aguiar. Rio de Janeiro: Zahar, 2018. 251p.

LIMA, Francisco Jozivan. O Novo Coronavírus e os impactos na vida dos mais pobres: capitalismo e aporofobia. In: SOBRINHO, Liton et.al (org.). Covid-19: Direitos Humanos e Educação. Itajaí: Univali, 2020. p. 175 - 187.

LUBENOW, Jorge Adriano. Esfera Pública e Democracia Deliberativa em Habermas: modelo teórico e discursos práticos, Revista kriterion, Belo Horizonte, n.121, p.227 - 258, 2010.

MÉSZÁROS, István. O poder da Ideologia. Tradução Paulo Castanheira. São Paulo: Boitempo, 2004. 559p.

MONTESQUIEU. Do Espírito das Leis. Tradução Jean Melville. São Paulo: Martin Claret, 2007. 727p.

NOBRE, Marcos. Ponto Final: A guerra de Bolsonaro contra a democracia. 1.ed. São Paulo: Todavia, 2020. 80p.

NOBRE, Marcos (org.). Curso Livre de Teoria Crítica. Campinas: Papirus, 2008. 302p.

PARIJS, Philippe Van, VANDERBORGHT, Yannick. BASIC INCOME: A Radical Proposal for a Free Society and a Sane Economy. Cambridge: Harvard University Press, 2017. $384 \mathrm{p}$.

PINZANI, Alessandro, REGO, Walquiria Leão. Vozes do Bolsa Família: autonomia, dinheiro e cidadania. São Paulo: Unesp, 2013a. 241p.

PINZANI, Alessandro. Justiça social e carências. In: PINZANI, Alessandro, TONETTO, Milene (org.). Teoria Crítica e Justiça Social. Florianópolis: Nefiponline, 2013b. 216p.

PINZANI, Alessandro. De objeto de políticas a sujeitos da política: dar voz aos pobres, Revista ethic@, Florianópolis, v. 10, n. 3, p. 83 - 101, 2011.

ROSA, Hartmut. Aceleração: a transformação das estruturas temporais na modernidade. Tradução Rafael Silveira. São Paulo: Unesp, 2019. 681p. 
SAFATLE, Vladimir, JUNIOR, Nelson da Silva et.al. (org.). Patologias do Social: Arqueologias do sofrimento psíquico. 1. ed. Belo Horizonte: Autêntica, 2018. 267p.

SCHWARCZ, Lilia. Sobre o autoritarismo brasileiro. São Paulo: Companhia das Letras, 2019. 273p.

SEN, Amartya. Poverty and Famines: An Essay on Entitlement and Deprivation. Oxford: Clarendon Press, 1981. 257p.

SANTOS, Boaventura de Sousa. Renovar a teoria crítica e reinventar a emancipação social. Tradução Mouzar Benedito. São Paulo: Boitempo, 2007. 126p.

SILVA, Josué Pereira da. Sociologia crítica e a crise da esquerda. São Paulo: Intermeios, 2019. 224p.

SOBRINHO, Liton et.al (org.). Covid-19: Direitos Humanos e Educação. Itajaí: Univali, 2020. 457p.

SOUZA, Jessé. A Guerra contra o Brasil. Rio de Janeiro: Estação Brasil, 2020. 248p.

A classe média no espelho: sua história, seus sonhos e ilusões, sua realidade.

Rio de Janeiro: Estação Brasil, 2018a. 247p.

Subcidadania brasileira: para entender o país além do jeitinho brasileiro. Rio de Janeiro: Leya, 2018b. 288p.

STAHL, Titus. Immanente Kritik: Elemente einer Theorie sozialer Praktiken. Frankfurt am Main: Campus Verlag, 2013. 475p.

STRECK, Lenio Luiz. Verdade e Consenso: Constituição, Hermenêutica e Teorias Discursivas da possibilidade à necessidade de respostas corretas em direito. 3.ed. rev. ampl. Rio de Janeiro: Lumen Juris, 2009. 594p.

TAVARES, André et al.(org.). Estado Constitucional e organização do poder. São Paulo: Saraiva, 2010. 549p.

WESCHE, Tilo. Reflexion, Therapie, Darstellung: Formen der Kritik. In: JAEGGI, Rahel, WESCHE, Tilo (orgs.). Was ist Kritik? 3.ed. Frankfurt am Main: Suhrkamp, 2013. p.193 220. 